\title{
Reverse Translation of Clinical Electrophysiological Biomarkers in Behaving Rodents under Acute and Chronic NMDA Receptor Antagonism
}

\author{
Elyse M Sullivan', Patricia Timi', L Elliot Hong ${ }^{2}$ and Patricio O’Donnell*,1,2,3 \\ 'Department of Anatomy and Neurobiology, Maryland Psychiatric Research Center, University of Maryland School of Medicine, Baltimore, MD, \\ USA; ${ }^{2}$ Department of Psychiatry, Maryland Psychiatric Research Center, University of Maryland School of Medicine, Baltimore, MD, USA
}

\begin{abstract}
Electroencephalogram (EEG) stands out as a highly translational tool for psychiatric research, yet rodent and human EEG are not typically obtained in the same way. In this study we developed a tool to record skull EEG in awake-behaving rats in a similar manner to how human EEG are obtained and then used this technique to test whether acute NMDA receptor antagonism alters rodent EEG signals in a similar manner as in humans. Acute MK-80I treatment elevated gamma power and reduced beta band power, which closely mirrored EEG data from healthy volunteers receiving acute ketamine. To explore the mechanisms behind these oscillatory changes, we examined the effects of GABA-A receptor blockade, finding that picrotoxin (PTX) recapitulated the decrease in sound-evoked beta oscillations observed with acute MK-80I, but did not produce changes in gamma band power. Chronic treatment with either PTX or MK-80 I did not affect frequency-specific oscillatory activity when tested $24 \mathrm{~h}$ after the last drug injection, but decreased total broadband oscillatory power. Overall, this study validated a novel platform for recording rodent EEG and demonstrated similar oscillatory changes after acute NMDA receptor antagonism in both humans and rodents, suggesting that skull EEG may be a powerful tool for further translational studies.

Neuropsychopharmacology (2015) 40, 719-727; doi:I0.1038/npp.2014.228; published online 24 September 2014
\end{abstract}

\section{INTRODUCTION}

A significant hurdle to research on the pathophysiology and treatment of major psychiatric disorders is that these conditions are difficult to model in animals. Although much effort has been put into establishing useful rodent models, it is essential to identify aspects of rodent brain physiology that are analogous and, when possible, homologous to human brain physiology, through validated crossspecies biomarkers. Electroencephalogram (EEG) is one of the few techniques for measuring neural activity during resting, sensory, and cognitive tasks that can be recorded in rodents and humans alike. EEG is, therefore, a candidate translational biomarker that may allow us to conduct parallel studies across species (Luck et al, 2011). EEG abnormalities are well characterized in schizophrenia (Cho et al, 2006; Hong et al, 2012; Rutter et al, 2009; Uhlhaas and Singer, 2010), bipolar disorder (Clementz et al, 1994), alcohol dependence (Costa and Bauer, 1997), and other psychiatric conditions. Previous studies have assessed EEG

*Correspondence: Dr P O'Donnell, Neuroscience Research Unit, Pfizer, 610 Main Street, Cambridge, MA 02139, USA, Tel: + I 6173950838 , Fax: + I 845474 4276, E-mail: Patricio.odonnell@pfizer.com

${ }^{3}$ Current address: Neuroscience Research Unit, Pfizer, 610 Main Street, Cambridge, MA 02139, USA

Received 6 May 20 14; revised 7 August 20 I4; accepted 8 August 2014; accepted article preview online I September 2014 and evoked potentials in rodent models (Bickel et al, 2008; Broberg et al, 2010; Dissanayake et al, 2009; Ehrlichman et al, 2009b; Hakami et al, 2009; Vohs et al, 2009), and recent evidence suggests surface EEG is correlated with neural synchrony among local field potential (LFP) sites (Musall et al, 2014). However, the results are difficult to compare with human data due to very different approaches in how the signals are acquired and processed. Animal EEG recordings are routinely conducted with electrodes in direct contact with brain tissue with field electrodes or screws driven through the skull. A direct contact with brain tissue captures strong local signals that mask EEG data, whereas human EEG signals are greatly attenuated by non-conductive tissue (ie, the skull and skin). Therefore, questions remain on how well low-powered high-frequency components are represented in scalp EEG.

The first goal of this study was to create a tool to record skull EEG in awake-behaving rats in a similar manner to how human EEG are obtained and then test whether rodent EEG signals are altered similarly to human EEG under acute NMDA receptor antagonism. We chose NMDA receptor blockade because of its well-characterized effects on human EEG (Hong et al, 2010) and extensive use in human research to model aspects of schizophrenia (Krystal et al, 1994; Malhotra et al, 1996; Rowland et al, 2005a). To further minimize methodological differences between human and rodent EEG, we used an auditory-evoked potential (AEP) paradigm and processed rodent EEG data using the 
wavelet-based signal processing we previously used in human studies (Hong et al, 2008a, 2010). We analyzed evoked power by presenting both pre- and post-stimulus data instead of their ratio, in order to avoid assumptions as to whether pre- and post-stimulus oscillations interact. In all, we are applying our established analytical tools in human neurophysiology studies to rodent EEG data.

The intent of reverse translational studies is not simply to replicate human observations, but also to explore the mechanism behind these phenomena by utilizing experimental approaches in animals that cannot be carried out in humans. Thus, in addition to recording skull EEG, we simultaneously obtained LFP from the primary auditory cortex (A1) and hippocampus (HP) to explore the regional specificity of oscillatory signals. Furthermore, given the strong evidence for GABAergic abnormalities in psychiatric disorders and the dependence of NMDA antagonism on inhibitory interneuron suppression, we expanded our pharmacological manipulations to study the oscillatory effects of GABA-A antagonism. Finally, we examined the consequences of chronic treatment with NMDA receptor and GABA-A antagonists for EEG and LFP signals.

\section{MATERIALS AND METHODS}

\section{Animals and Surgery}

All procedures were conducted according to the USPHS Guide for the Care and Use of Laboratory Animals, and were approved by the University of Maryland School of Medicine Institutional Animal Care and Use Committee. Adult male Sprague-Dawley rats $(n=18)$ were purchased from Charles River Laboratories (Wilmington, MA) and group-housed (3 per cage) upon arrival in a room maintained at $23^{\circ} \mathrm{C}$ with a 12-h light/dark cycle (lights on at 0700 hours) with ad libitum access to food and water. Rats were allowed 2 weeks of acclimation to the animal facility before electrode implantation. Electrode arrays (Innovative Neurophysiology, Durham, NC) consisting of skull EEG electrodes and microwires for deep recordings $(35 \mu \mathrm{m}$ in diameter; Figure 1) were implanted in rats $(400-$ $450 \mathrm{~g}$ ) under isoflurane anesthesia (5\% of oxygen for induction and 2-3\% for maintenance). Skull EEG electrodes consisted of $2 \mathrm{~mm}$ diameter $\mathrm{Ag} / \mathrm{AgCl}$ disks that were cemented onto the skull surface at bregma, equivalent to the human vertex EEG site. Deep electrodes were implanted in A1 $(5.2 \mathrm{~mm}$ caudal from bregma, $6.5 \mathrm{~mm}$ lateral to midline, $2.2 \mathrm{~mm}$ ventral to dura) and the CA1 region of the HP $(5.2 \mathrm{~mm}$ caudal from bregma, $5.5 \mathrm{~mm}$ lateral, $3.8 \mathrm{~mm}$ from dura), and secured with dental cement. Carprofen $(5 \mathrm{mg} / \mathrm{kg}$ i.p.) was given once daily for $72 \mathrm{~h}$ post surgery. Rats were allowed 3 weeks recovery before recordings. At the end of the study, rats were anesthetized with chloral hydrate and transcardially perfused with $0.9 \%$ saline followed by $4 \%$ paraformaldehyde. Brains were removed and sectioned at $50 \mu \mathrm{m}$ on a freezing microtome. Electrode tracts were identified as small lesions in the tissue using a rat brain atlas (Paxinos and Watson, 1998). Only animals with appropriate electrode placement in A1 and HP were used for analyses.
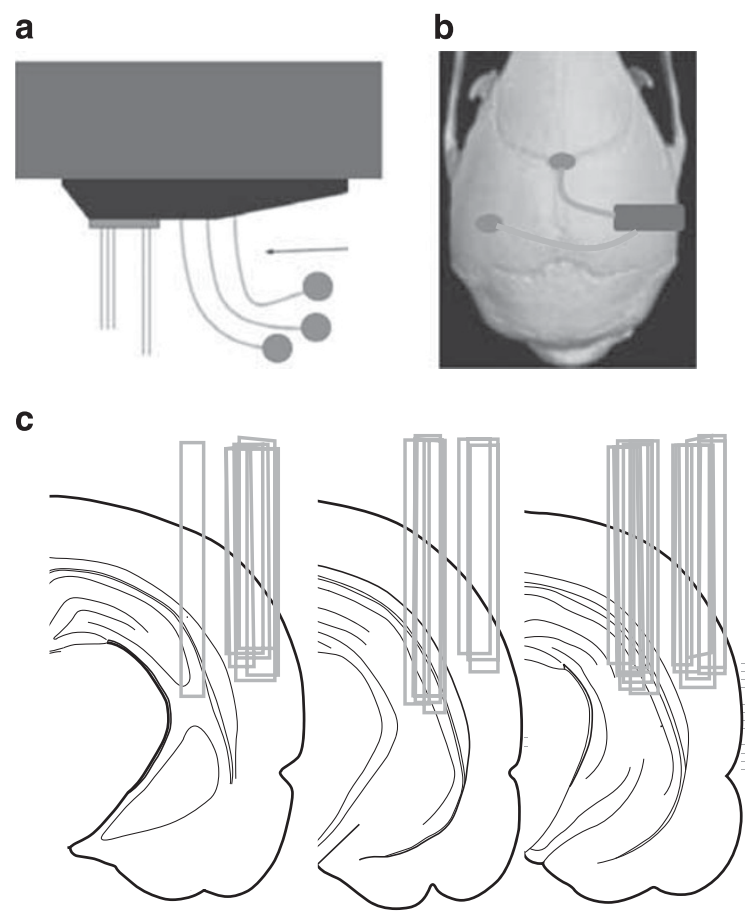

Figure I Electrode placement diagram. (a) Schematic of electrodes used with EEG disc electrodes illustrated in green and local field potential (LFP) electrodes in gray. (b) Illustration of skull surface electroencephalogram placement (green discs). (c) Placement of LFP electrodes in AI cortex and HP. Each bar represents the placement of electrode arrays as verified by histology. Data from animals with improper placement were excluded from the analysis. A full color version of this figure is available at the Neuropsychopharmacology journal online.

\section{Recordings in Behaving Rats}

Recording sessions were conducted in clear $12^{\prime} \times 12^{\prime}$ plexiglass boxes (Med Associates, St. Albans, VT) housed within a sound-attenuated chamber. Rats were given three sessions of $30 \mathrm{~min}$ each to habituate to the recording box and to being plugged in and tethered to the commutator (Plexon, Dallas, TX). Electrophysiological signals were sampled at $1 \mathrm{kHz}$ using a 32-channel Omniplex system (Plexon). Tones were driven by an RZ6 system (Tucker Davis Technologies, Alachua, FL) and delivered via speakers mounted in the recording chambers. After $10 \mathrm{~min}$ of habituation, rats were presented with 200 pairs of single white-noise sounds (1 ms, $75 \mathrm{~dB}$ clicks) with $500-\mathrm{ms}$ intervals with a jittered time interval between the click pairs $(2 \pm 0.5 \mathrm{~s})$. Sound parameters were the same as those used in humans (Hong et al, 2008b, 2010). We assessed oscillations during presentation of the first click (S1) and gating of evoked oscillations by calculating the ratio of the amplitudes of responses to the second click (S2) divided by the response to the $\mathrm{S} 1$.

\section{Acute and Chronic Drug Treatment}

After three baseline recording sessions on consecutive days with no drug or vehicle injection, all rats were recorded under acute $(+)$-MK- 801 hydrogen maleate $(0.1 \mathrm{mg} / \mathrm{kg}$, i.p.; Sigma, St Louis, MO), picrotoxin (PTX) $(0.5 \mathrm{mg} / \mathrm{kg}$, i.p.; 
Sigma), or saline. MK-801 was chosen as opposed to ketamine for this study due to its substantially longer action in rodents (Hakami et al, 2009; Pinault, 2008) and increased specificity for NMDA receptors (Miyamoto et al, 2000). In addition, previous studies using LFP recordings found similar effects of ketamine and $\mathrm{MK}-801$ on oscillatory activity (Hakami et al, 2009; Pinault, 2008). Rats were given i.p. injections and placed in the recording chamber to habituate for $15 \mathrm{~min}$ before recording. After the acute recording day, each animal was subsequently injected daily in their home cage for 21 days. This study was conducted in a counterbalanced crossover design. Animals were randomly assigned into one of three groups: MK-801-PTX, PTX-MK-801, or saline-saline. Baseline recordings were followed by acute drug administration and testing, daily injection for 21 days, and finally chronic testing in the drugfree state 1 day after the last injection. All rats had a 3-week washout period during which they remained in their home cage. Following this washout period, the group that previously received acute and chronic MK-801 was switched to acute and chronic PTX and vice versa.

\section{Signal Processing and Analysis}

We used Neuroscan v5.4 (Compumedics, El Paso, TX) to analyze sound-evoked oscillations. EEG signals from the S1 response obtained during the paired-sound task were filtered at $1-180 \mathrm{~Hz}$, and sorted into $300-\mathrm{ms}$ post-stimulus epochs. An automated artifact rejection using an amplitude filter at $\pm 300 \mu \mathrm{V}$ was used for all data to reject contaminated trials. This was followed by visual inspection of EMG and EEG data for movement-contaminated trials. The average number of trials used for each animal was 144.6 \pm 23.5 . We employed data analysis methods identical to those used in human studies (Hong et al, 2008b, 2010) to maximize comparability between the species. To evaluate evoked power at different frequency bands of each single trial, we used an eight-level discrete biorthogonal wavelet (MathWorks) to separate evoked responses into eight details representing eight frequency bands. By simulation, we estimated the frequency bands of each detail: D1-D3 correspond to very high gamma frequencies $(>85 \mathrm{~Hz}), \mathrm{D} 4$ : 40-85 Hz (gamma), D5: 20-40 Hz (low gamma), D6: 12$20 \mathrm{~Hz}$ (beta), D7: 5-12 Hz (theta-alpha), D8: 1-5 Hz (delta). This method measured oscillations in single trials that include both stationary and non-stationary oscillatory responses associated with the stimulus, rather than only the stationary, time-locked component as in averaged AEP. The Energy within each frequency band was measured by power spectrum density (PSD) using a Welch method. The PSD in each frequency range from the accepted trials were then averaged. We converted the PSD data from each subject into relative power by normalizing the power in each frequency band to the total power in the $1-180 \mathrm{~Hz}$ range.

We also calculated the averaged AEP in response to $\mathrm{S} 1$ and S2 to measure sensory gating. We filtered the EEG signals from individual animals using a $1-180-\mathrm{Hz}$ bandpass filter, normalized to a $100-\mathrm{ms}$ pre-stimulus interval, epoched, and averaged across trials. The P1 and N1 components were identified from the averaged AEP. We defined $\mathrm{P} 1$ as the first positive-going wave occurring between 10 and $45 \mathrm{~ms}$ post stimulus, and the N1 component as the first negative-going component directly following P1 between 20 and $70 \mathrm{~ms}$ post stimulus. N1 and P1 were automatically identified for S1 and S2, which were then visually verified. We calculated sensory gating as the S2/S1 ratio for $\mathrm{N} 1$ and $\mathrm{P} 1$.

\section{Statistical Methods}

SPSS and Graphpad programs were used for statistical analyses. For sound-evoked oscillations, we used a two-way repeated-measures ANOVA to compare the power in five frequency bands (gamma, high beta, low beta, theta-alpha, and delta) across recording sessions. All data passed the Shapiro-Wilks test of normality and violations of sphericity were subjected to Greenhouse-Geisser correction when necessary. For P1 and N1 gating, we used one-way repeatedmeasures ANOVAs to compare across recording sessions. Bonferroni post hoc tests were used for multiple comparisons following significant ANOVA.

\section{RESULTS}

\section{Oscillatory Responses to Auditory Stimuli with Acute NMDA Receptor Antagonism}

Acute MK-801 (0.1 mg/kg, i.p.) altered oscillatory power recorded with skull surface EEG. Repeated-measures ANOVA on five frequency bands during baseline (predrug) and acute MK-801 showed a significant frequency by session interaction $\left(F_{(4,40)}=5.560, p=0.001\right)$ without affecting total broadband power $\left(1-180 \mathrm{~Hz} ; t_{(10)}=0.731\right.$, $p=0.482)$. Post hoc tests revealed a significant increase in gamma $\left(40-85 \mathrm{~Hz} ; t_{(10)}=3.956, p=0.003\right)$ and decrease in beta $\left(12-20 \mathrm{~Hz} ; t_{(10)}=4.551, p=0.001\right)$ power with acute MK-801 (Figure 2). Thus, NMDA receptor blockade causes a shift from low to high evoked EEG frequencies in rats. When analyzing the pre-stimulus period, we found a similar frequency by session interaction $\left(\mathrm{F}_{(4,40)}=6.400, p<0.001\right)$ with a significant elevation of gamma power $(40-85 \mathrm{~Hz}$; $\left.t_{(10)}=3.900, p=0.003\right)$ and a decrease in beta power (12$\left.20 \mathrm{~Hz} ; t_{(10)}=3.269, p=0.008\right)$, suggesting that acute MK801 has a similar effect on EEG oscillations at rest and during auditory sensory processing.

In order to establish correlates of activity in brain regions important for processing sensory information thought to be disrupted in schizophrenia, we simultaneously recorded LFP responses from the A1 cortex and the CA1 region of the $\mathrm{HP}$, observing a pattern similar to skull surface EEG. In the $\mathrm{HP}$, we found a significant frequency by session interaction $\left(\mathrm{F}_{(4,32)}=3.674, p=0.014\right)$, and post hoc tests revealed that acute MK-801 increased gamma power $\left(t_{(8)}=3.590\right.$, $p=0.007)$ and decreased beta power from baseline $\left(t_{(8)}=2.743, p=0.025\right)$. In the A1 cortex, the frequency by session interaction $\left(\mathrm{F}_{(4,40)}=2.291, p=0.076\right)$ did not reach statistical significance. There was no change in total broadband power in the HP $\left(t_{(8)}=1.873, p=0.098\right)$ or the A1 cortex $\left(t_{(10)}=1.599, p=0.141\right)$ after acute MK-801 administration. Thus, HP activity may correlate more closely with surface-evoked EEG oscillations than A1 cortex under this paradigm. 
a
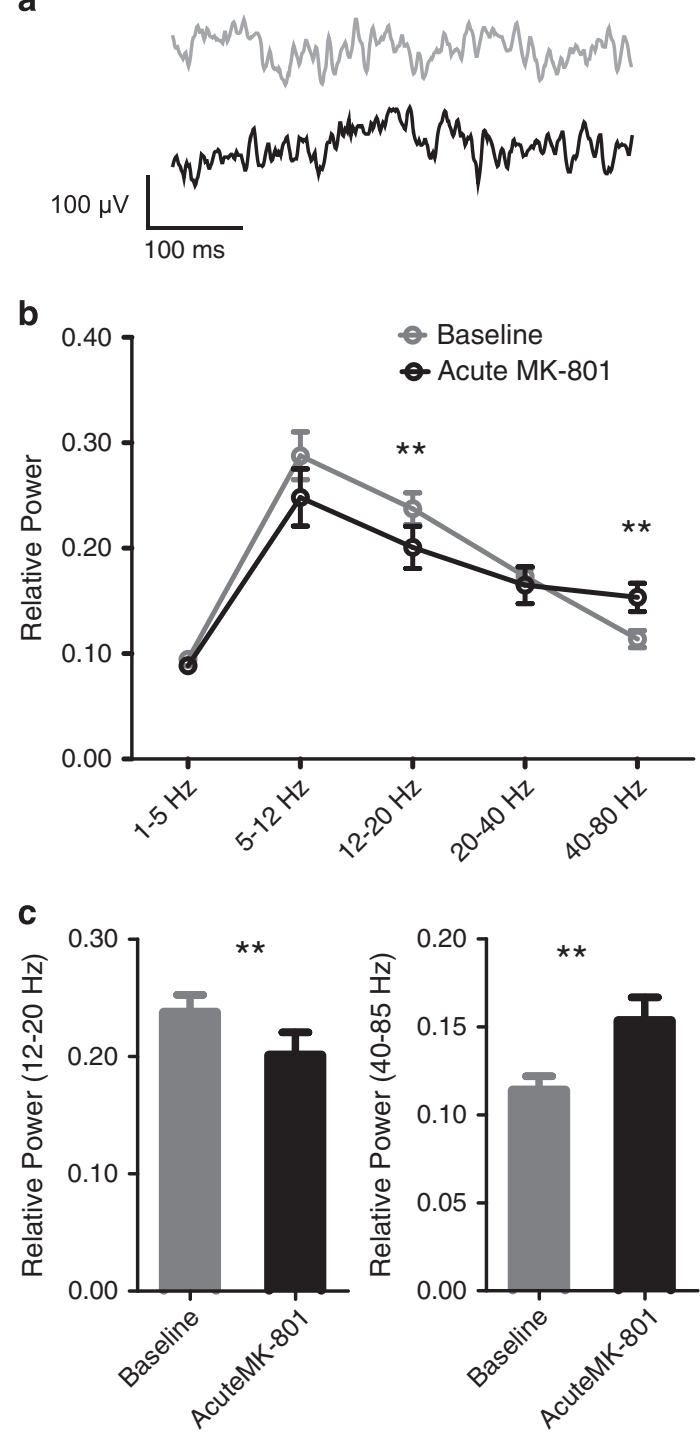

Figure 2 Acute effect of MK-80I on sound-evoked oscillations in awake, unrestrained rats. (a) Representative EEG traces at baseline (gray) and after acute MK-80 I (red). (b) Power spectrum density (PSD) plot of vertex EEG signal from 12 rats during a $300 \mathrm{~ms}$ post-stimulation epoch across 5 frequency bands at baseline and after MK-80 I (0.I mg/kg i.p.). Baseline data shown are average values of the three baseline sessions for each animal. Acute MK-80 I data is from a single session after acute MK-80 I injection. We normalized the evoked power in each of the 5 frequency bands to the total power for each subject, represented here as relative power. Acute MK-80 I significantly increased tone-evoked gamma power $(40-85 \mathrm{~Hz})$, while decreasing beta power $(12-20 \mathrm{~Hz})$ compared with baseline. (c) Bar graphs show enlarged relative power in the gamma band (right) and decreased relative power in the beta band (left). In this and subsequent figures, all data are plotted as mean \pm SEM $(* * p<0.0 I)$.

\section{Oscillatory Responses to Auditory Stimuli with Acute GABA-A Receptor Blockade}

As NMDA blockade has been proposed to exert its effects by selectively inactivating NMDA receptors in cortical GABA interneurons (Homayoun and Moghaddam, 2007), we next explored whether GABA-A blockade reproduced the effects of NMDAR antagonists. The GABA-A channel blocker PTX also affected oscillations. We found a significant frequency a

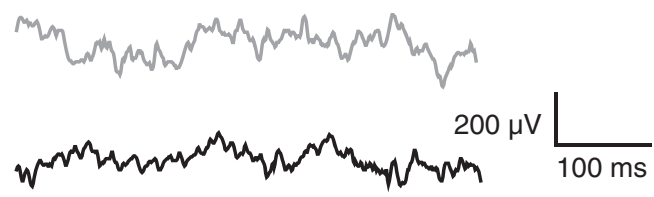

b
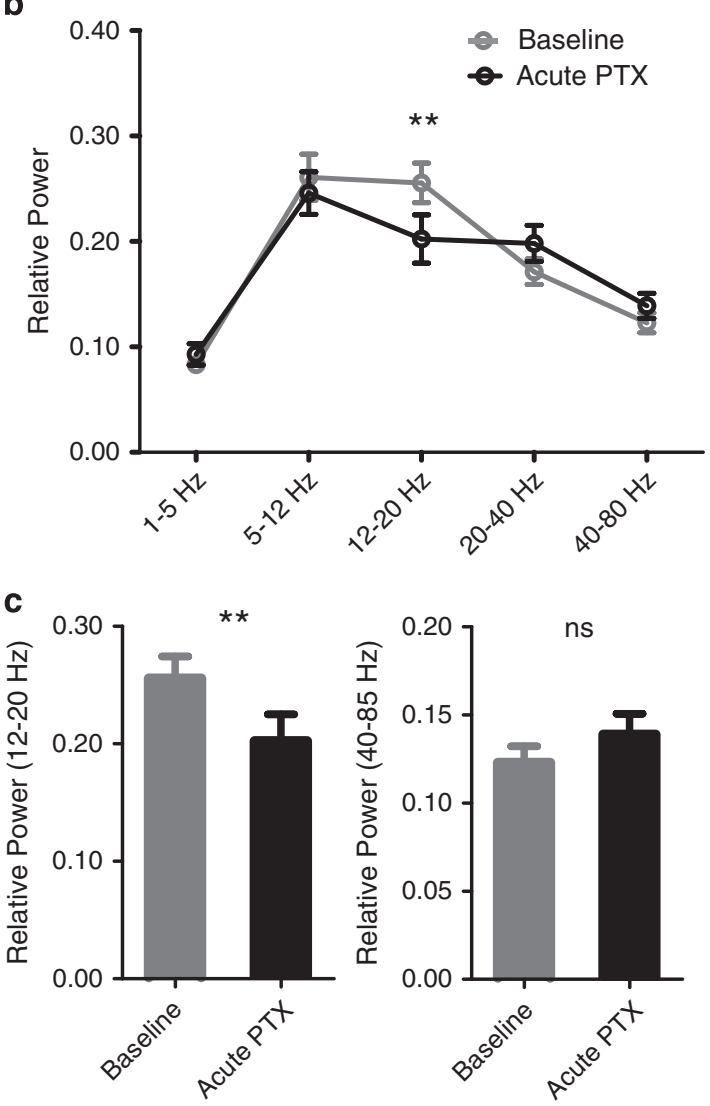

Figure 3 Acute effect of picrotoxin on tone-evoked oscillations in freely moving rats. (a) Representative EEG traces at baseline (gray) and after acute PTX (green). (b) Power spectrum density (PSD) plot of vertex EEG signal from 12 rats during a 300-ms post-stimulation epoch across 5 frequency bands at baseline and after PTX $(0.5 \mathrm{mg} / \mathrm{kg}$ i.p.). Baseline data shown are average values of the three baseline sessions for each animal. Acute PTX data is from a single session after acute PTX injection. We normalized the evoked power in each of the 5 frequency bands to the total power for each subject, represented here as relative power. Acute PTX significantly decreased tone-evoked beta power $(12-20 \mathrm{~Hz})$ compared with baseline, but had no significant effect on gamma band power. (c) Bar graphs shows decreased relative power in the beta band (left) and no difference in the gamma band (right).

by session interaction $\left(\mathrm{F}_{(4,40)}=5.543, p=0.001\right)$, and post hoc tests showed that acute PTX $(0.5 \mathrm{mg} / \mathrm{kg})$ reduced beta band power from baseline $\left(t_{(10)}=4.557, p=0.001\right)$, similar to the effect of acute MK-801, but there was no significant difference in gamma band power. As with acute MK-801, total broadband power was not altered with acute PTX $\left(t_{(10)}=1.382, p=0.197\right.$; Figure 3). In contrast to what we observed with acute MK-801, we found no significant frequency by session interaction in the pre-stimulus epoch, suggesting that the reduction in beta power by GABA-A blockade may only be evident during auditory sensory 
a
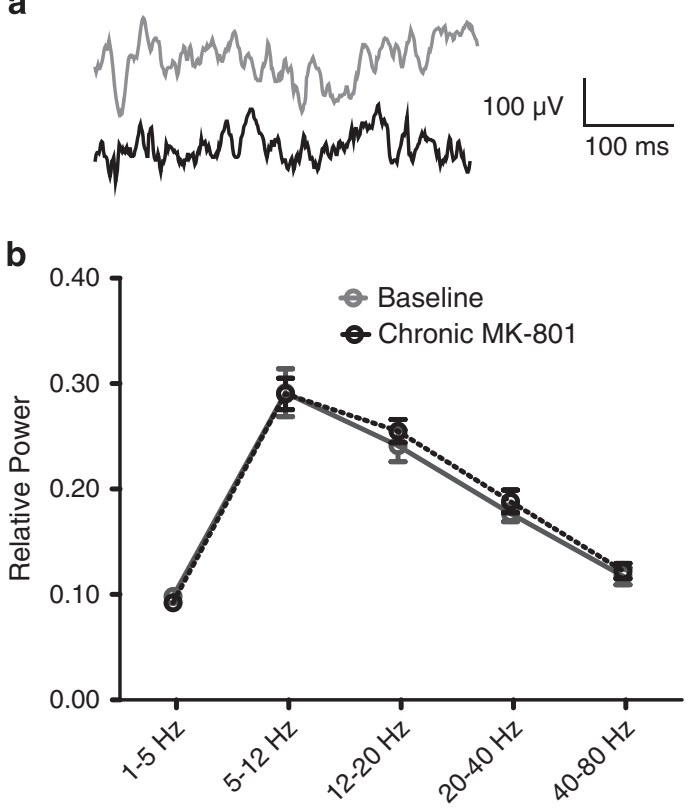

C
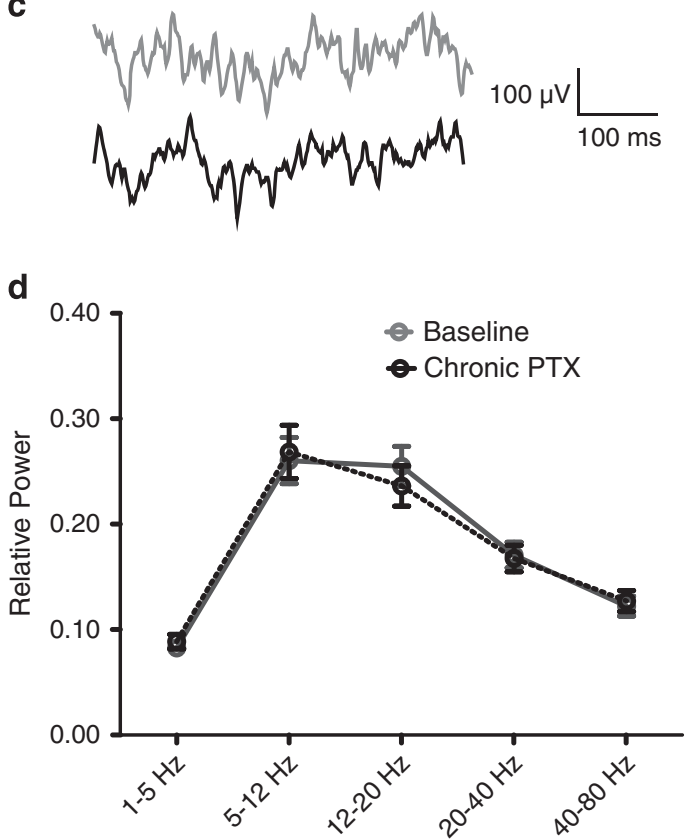

Figure 4 Chronic effect of MK-80I or PTX on tone-evoked oscillations in freely moving rats. ( $a$ and $b$ ) Power spectrum density (PSD) plot of vertex EEG signal from 12 rats during a 300 ms post-stimulation epoch across 5 frequency bands at baseline and after 21 days of MK-80 I $(0.1 \mathrm{mg} / \mathrm{kg}$ i.p.) or PTX $(0.5 \mathrm{mg} / \mathrm{kg}$ i.p). Baseline data shown are average values of the three baseline sessions for each animal. Chronic data is recorded $24 \mathrm{~h}$ after the last chronic injection in the drug-free state. We normalized the evoked power in each of the 5 frequency bands to the total power for each subject, represented here as relative power. Neither chronic MK-80I nor PTX significantly altered tone-evoked oscillations compared with baseline.

processing. To ensure the lack of response to PTX was not due to insufficient dosing, we tested a subset of rats $(n=4)$ with a higher dose $(1.0 \mathrm{mg} / \mathrm{kg})$ and found that three out of the four rats developed seizures within 20 min of injection. Therefore, the $0.5 \mathrm{mg} / \mathrm{kg}$ PTX dose was likely close to a maximal dose without epileptogenic activity. The data suggest that MK-801-induced reduction in beta, but not increased gamma, oscillations could be mediated by an attenuation of local inhibitory processes. We also analyzed oscillations in the HP and Al cortex and did not find a significant frequency by session interaction at either location $\left(\mathrm{HP}: \mathrm{F}_{(4,32)}=1.072, p=0.382 ; \mathrm{A} 1: \mathrm{F}_{(4,32)}=1.087\right.$, $p=0.376)$.

\section{Oscillatory Responses to Auditory Stimuli with Chronic NMDA Receptor Antagonism}

Acute NMDAR blockade may be insufficient to model longlasting electrophysiological changes associated with psychiatric disorders. To explore the consequences of sustained NMDAR blockade, we treated rats with MK-801 $(0.1 \mathrm{mg} / \mathrm{kg})$ for 21 days. EEG was recorded prior to treatment and again on day 22 (one day after drug cessation) to determine whether chronic exposure would lead to changes in oscillations even when the animal no longer had the drug in their system (half-life of MK-801 is $2 \mathrm{~h}$ ) (Vezzani et al, 1989). When comparing oscillatory power after 21 days of chronic MK-801 with power at baseline, we found no session by frequency interaction $\left(\mathrm{F}_{(4,40)}=0.503, p=0.733\right)$, suggesting chronic NMDA antagonism did not change power when MK-801 was absent (Figure 4). We did find a decrease in total broadband power after chronic MK-801 $\left(t_{(10)}=2.941, p=0.015\right)$ in the absence of any significant changes in a given bandwidth. This suggests that prolonged exposure to MK-801 may function to dampen EEG oscillatory power across all frequency bands. However, we did not find a significant decrease in total power in the HP $\left(t_{(8)}=1.162, p=0.279\right)$ or A1 $\left(t_{(10)}=1.599, p=0.141\right)$. As a control for possible effects of injection procedures in EEG responses, 6 rats were exposed to saline acutely or chronically for 21 days. No effects were detected on oscillatory power after acute and chronic exposures (frequency by session interaction: $\mathrm{F}_{(8,40)}=1.483$, $p=0.194)$. We also failed to observe significant changes in power following chronic $\operatorname{PTX}\left(\mathrm{F}_{(4,40)}=0.908, p=0.469\right.$; Figure $4 \mathrm{~b}$ ) with no change in total broadband power in the $\operatorname{EEG}\left(t_{(10)}=0.112, p=0.913\right)$, HP $\left(t_{(8)}=1.794, p=0.111\right)$, or A1 $\left(t_{(10)}=1.650, p=0.130\right)$.

\section{Gating of Skull-Recorded Averaged AEP}

A common feature of schizophrenia is the inability to ignore irrelevant external information, evidenced by impairments in sensory gating (Adler et al, 1982; Freedman et al, 1983). In the same experiments, we assessed AEP gating and their modulation by MK-801, PTX, or saline. P1 amplitude at S1 showed an overall significant effect when comparing baseline, acute MK-801, and chronic MK-801 $\left(\mathrm{F}_{(2,18)}=7.210\right.$, $p=0.005)$, although post hoc tests only revealed a significantly higher P1 amplitude in acute compared with chronic MK-801 $\left(t_{(9)}=3.032, p=0.014\right)$, and no differences between baseline and acute or chronic MK-801 ( $p>0.05$; Figure 5). When comparing baseline, acute PTX, and chronic PTX, there was no significant effect of P1 amplitude at S1 $\left(\mathrm{F}_{(2,20)}=0.607, p=0.554\right)$. We also tested if there were changes in N1 amplitude, and found that at S1 there was no significant effect when comparing baseline, acute MK-801, and chronic MK-801 $\left(\mathrm{F}_{(2,18)}=2.281, p=0.131\right)$ or PTX 
a

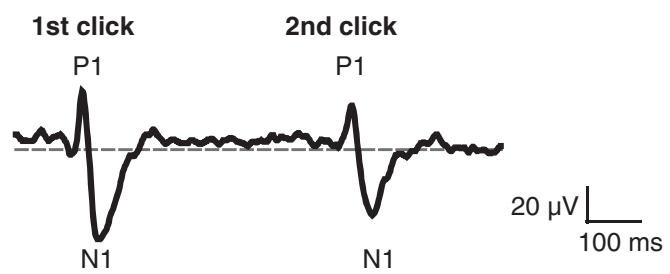

b

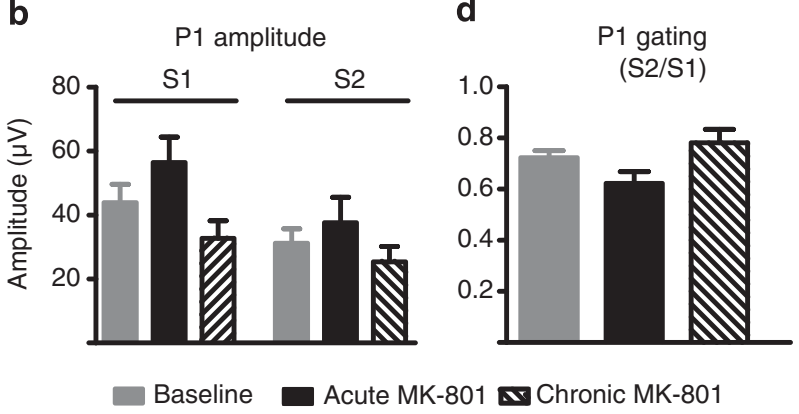

C
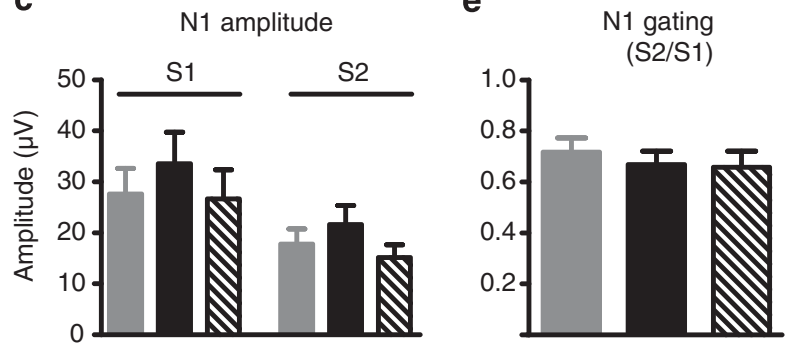

Figure 5 Gating of average-evoked potentials in response to paired sounds. (a) Representative auditory-evoked potential during the pairedclick paradigm, illustrating a reduction of $\mathrm{PI}$ and $\mathrm{NI}$ amplitudes in response to the second tone (S2) compared with the first (SI). (b-d) Bar graph representation of $\mathrm{PI}$ and $\mathrm{NI}$ peak amplitudes in response to the first click (SI) and the second click (S2) at baseline (gray), with acute MK-80I (red), and with chronic MK-80I (red-striped). No significant differences in peak amplitudes were found with acute or chronic MK-80I compared with baseline. (c-e) Auditory sensory gating of $\mathrm{PI}$ and $\mathrm{NI}$ components obtained by dividing the peak amplitude evoked by $\mathrm{S} 2$ by the peak amplitude evoked by $\mathrm{SI}$. All groups demonstrated gating of the response of $\mathrm{S} 2$ relative to $\mathrm{SI}$, however, acute or chronic MK-80I treatment did not alter this gating from baseline.

$\left(\mathrm{F}_{(2,20)}=0.449, p=0.644\right)$. Neither $\mathrm{P} 1$ gating nor $\mathrm{N} 1$ gating showed differences when comparing baseline, acute MK-801, and chronic MK-801 (P1 gating: $\mathrm{F}_{(2,18)}=3.124, p=0.069 ; \mathrm{N} 1$ gating: $\mathrm{F}_{(2,18)}=0.3382, \quad p=0.718$ ) or PTX (P1 gating: $\mathrm{F}_{(2,20)}=0.995, p=0.386 ; \mathrm{N} 1$ gating $\left.\mathrm{F}_{(2,20)}=0.204, p=0.817\right)$.

\section{DISCUSSION}

In an effort to optimize EEG as a translational tool, we developed a method of acquiring skull surface EEG in awake-behaving rats that resembles how EEG is acquired in humans. Acute NMDAR antagonism using MK-801 significantly increased vertex EEG gamma power and reduced beta frequency power in awake-behaving rats during an auditory-evoked paradigm. To explore the mechanisms behind altered oscillations, we used the GABA-A receptor antagonist PTX, which reduced vertex EEG beta power similarly to acute MK-801, but did not affect gamma band power. These effects suggest that the increase in gamma power induced by NMDAR antagonism may be due to actions on a specific subtype of GABAergic interneurons and not on an overall reduction in interneuron activity. The lack of effect on gamma band by PTX does not appear to be due to low dose because we used a dose close to what is required to induce seizures. Acute MK-801 also increased gamma and reduced beta power in the HP, but not in A1. We also examined the effects of chronic NMDAR antagonist or GABA-A blockade on oscillations, but did not find any frequency-specific effect of 21-day MK-801 or PTX treatment on auditory-evoked EEG oscillations. We did, however, find a significant decrease in total EEG broadband power after chronic MK-801, suggesting there may be a general blunting of oscillatory activity.

EEG oscillations are useful tools to assess neural excitability and correlates of cortical disinhibition in a translational manner. These oscillations are thought to facilitate communication within and across brain regions (Uhlhaas and Singer, 2006b). In schizophrenia patients, neural oscillations are altered and may contribute to abnormal sensory and cognitive performance (Barr et al, 2010; Cho et al, 2006; Kwon et al, 1999; Mulert et al, 2011; Rutter et al, 2009; Spencer et al, 2003; Spencer et al, 2009; Uhlhaas et al, 2006a). Supporting rodent skull EEG as a useful translational tool, we found that acute MK-801 in rodents closely mirrors ketamine effects in healthy human volunteers (Hong et al, 2010). In a previous study, the same auditory paradigm and wavelet signal extraction used here revealed that acute ketamine significantly elevated gamma band oscillations at $40-85 \mathrm{~Hz}$ and reduced low-frequency oscillations at delta and theta-alpha bands $(1-12 \mathrm{~Hz})$ compared with placebo in humans (Hong et al, 2010). Although low-frequency decreases induced by ketamine in humans $(1-12 \mathrm{~Hz})$ and by MK-801 in rodents $(12-20 \mathrm{~Hz})$ slightly differ in the bandwidth involved, there is an overall similar pattern of shifting power from low to high frequencies with acute NMDAR antagonism in both humans and rodents. While not identical, these comparable results suggest that evoked EEG oscillations are highly translatable across species when recorded in a similar manner.

We also examined if AEP gating was affected by NMDAR antagonists in rodents and humans in a similar manner. Although AEP gating is impaired in schizophrenia patients (Adler et al, 1986; Freedman et al, 1983), it is not affected by ketamine when tested in healthy controls (Hong et al, 2010; Oranje et al, 2002; van Berckel et al, 1998), suggesting that NMDA receptors may not be critically involved in this AEP. Here, we found that neither acute nor chronic MK-801 treatment significantly altered the amplitude of the rat P1 or $\mathrm{N} 1$ components or the gating of $\mathrm{P} 1$ or $\mathrm{N} 1$ amplitudes. This lack of effect of MK-801 on AEP gating is consistent with what has been found with humans on ketamine, further supporting our ability to replicate human EEG findings in rodents.

NMDAR antagonists have been used extensively to probe questions related to the neurobiology of schizophrenia. Indeed, NMDAR antagonists such as ketamine consistently induce a schizophrenia-like psychotic state in healthy volunteers (Krystal et al, 1994; Luby et al, 1959; Malhotra et al, 1996), worsen psychosis in schizophrenia patients (Lahti et al, 1995), and improve depression (Berman et al, 
2000; Zarate et al, 2006). These drugs are hypothesized to produce psychotomimetic effects by creating a hyperexcitable state in the brain as evidenced by increased glutamate levels (Rowland et al, 2005b; Stone et al, 2012) and an elevation in global connectivity (Driesen et al, 2013). Furthermore, EEG studies have revealed alterations in excitation-inhibition balance following acute ketamine such as increased high-frequency and decreased low-frequency activity (Hong et al, 2010). Non-competing NMDAR antagonists are thought to preferentially act on GABAergic interneurons, perhaps due to their depolarized membrane potential or selective expression of NMDAR subunits with greater sensitivity to non-competing blockade such as GluN2C (Monyer et al, 1994). This selective action would reduce inhibitory influence on pyramidal cells and cause a net hyperexcitable circuit (O'Donnell, 2011). Consistent with this scenario, MK-801 has been shown to increase glutamate levels in the prefrontal cortex of rats (Moghaddam et al, 1997), while decreasing GABA levels (Yonezawa et al, 1998). The data we report here along with others (Ehrlichman et al, 2009a; Hakami et al, 2009; Lazarewicz et al, 2010Pinault, 2008) indicate that acute NMDAR antagonists produce robust elevations in gamma band activity. It is hypothesized that NMDAR antagonists may preferentially act at certain subtypes of GABAergic neurons to produce alterations in gamma activity. Indeed, optogenetic studies have shown that parvalbumin-expressing interneurons (PV-IN) are involved in the generation of gamma band oscillations (Cardin et al, 2009; Sohal et al, 2009). Thus, it is possible that alterations in PV-IN activity may underlie oscillatory changes driven by NMDAR antagonists. However, we did not observe any significant change in gamma band activity following acute GABA-A blockade. One possible explanation for the differential effects of PTX and MK-801 on gamma oscillations is that MK-801 could be acting on somatostatin-expressing interneurons, which inhibit both pyramidal cells and PV-IN, while PTX inhibits all GABAergic activity. On the other hand, the effect of MK-801 on beta oscillations was mimicked by GABA-A antagonism, suggesting that beta band activity may be driven by a different cellular mechanism than gamma oscillations. Our findings suggest that NMDA blockade effects on beta oscillations may be driven by overall loss of GABA-A activity, but the effects on gamma oscillations could be due to complex actions that may be limited to a subset of neurons.

We also assessed EEG effects of chronic administration of NMDAR and GABA-A antagonists. Previous studies have shown that, although acute ketamine increases frontal cortical blood flow (Breier et al, 1997; Lahti et al, 1995; Vollenweider et al, 1997), long-term ketamine or PCP use is associated with reduced frontal lobe blood flow and glucose utilization (Hertzmann et al, 1990). These data suggest that acute NMDAR antagonist administration may produce a hyperactive cortical state, but repeated or chronic NMDAR antagonist exposure may produce the opposite. Behavioral effects of chronic NMDAR antagonists in rodents have yielded mixed results with some tasks showing impairments (Abdul-Monim et al, 2007; Broberg et al, 2009; Hanania et al, 1999; Lee et al, 2005), while others are intact (Egerton et al, 2008). Very little is known about long-lasting neurophysiologic effects of chronic NMDAR antagonism. Our data show that, in contrast to the robust effects of acute MK-801 and PTX, chronic administration did not alter auditory-evoked oscillatory activity when tested in a drugfree state. However, we did find a significant decrease in total broadband power after chronic MK-801, but not PTX, suggesting that chronic MK-801may produce a blunting of oscillatory power across in a nonfrequency-specific manner. This is in line with previous studies showing reduced theta and gamma power after chronic or subchronic NMDAR antagonism (Featherstone et al, 2012; Kittelberger et al, 2012). Interestingly, these studies detected oscillatory effects several weeks or months after cessation of chronic NMDAR antagonism, suggesting that effects of chronic NMDAR antagonism may be long lasting. Our current study only tested the rats after $24 \mathrm{~h}$ of abstinence, and thus it is possible that we would have found stronger or more frequencyspecific effects after a longer duration of abstinence.

We have implemented a practical technique for recording skull surface EEG in awake-behaving rodents that resembles human EEG recording, while allowing for simultaneous intracortical recording. The majority of neurophysiological studies in rodents have used LFP recordings, which can provide more spatially localized oscillatory information. However, data acquired this way is less directly translatable to human EEG given the significant differences in signal attenuation and filtering, and the masking effect of local neural activity on a true EEG signal. The fact that our EEG findings in rodents with acute MK-801 closely mirror EEG data from humans on ketamine further supports the validity of this platform for translating between rodent and human EEG studies. Our approach also allowed us to directly compare skull EEG and intracortical signals within the same animals. We found that even though high-frequency oscillations comprise a small percentage of the total EEG signal, we were able to detect significant changes in these oscillations with acute NMDAR antagonists. This finding supports the legitimacy of high-frequency oscillatory data in human EEG studies. In fact, although we observed parallel oscillatory changes in the HP and skull surface EEG with NMDAR blockade, the pharmacological effect was actually stronger in the EEG signal. Overall, skull EEG electrodes have the potential to be a powerful translational tool for elucidating mechanisms behind altered oscillations in psychiatric disorders, and hold promise for future studies into mechanisms underlying oscillatory abnormalities across multiple disorders.

\section{FUNDING AND DISCLOSURE}

Patricio O'Donnell is employee and stockholder at Pfizer. Elliot Hong has received or is about to receive unrestricted research funding from Mitsubishi, Your Energy Systems LLC, and Pfizer. The authors declare no conflict of interest.

\section{ACKNOWLEDGEMENTS}

This work was supported by NIH grant R01 MH85226 (LEH and PO'D).

\section{REFERENCES}

Abdul-Monim Z, Neill JC, Reynolds GP (2007). Sub-chronic psychotomimetic phencyclidine induces deficits in reversal 
learning and alterations in parvalbumin-immunoreactive expression in the rat. J Psychopharmacol 21: 198-205.

Adler LE, Pachtman E, Franks RD, Pecevich M, Waldo MC, Freedman R (1982). Neurophysiological evidence for a defect in neuronal mechanisms involved in sensory gating in schizophrenia. Biol Psychiatry 17: 639-654.

Adler LE, Rose G, Freedman R (1986). Neurophysiological studies of sensory gating in rats: effects of amphetamine, phencyclidine, and haloperidol. Biol Psychiatry 21: 787-798.

Barr MS, Farzan F, Tran LC, Chen R, Fitzgerald PB, Daskalakis ZJ (2010). Evidence for excessive frontal evoked gamma oscillatory activity in schizophrenia during working memory. Schizophrenia Res 121: 146-152.

Berman RM, Cappiello A, Anand A, Oren DA, Heninger GR, Charney DS et al (2000). Antidepressant effects of ketamine in depressed patients. Biol Psychiatry 47: 351-354.

Bickel S, Lipp HP, Umbricht D (2008). Early auditory sensory processing deficits in mouse mutants with reduced NMDA receptor function. Neuropsychopharmacology 33: 1680-1689.

Breier A, Malhotra AK, Pinals DA, Weisenfeld NI, Pickar D (1997). Association of ketamine-induced psychosis with focal activation of the prefrontal cortex in healty volunteers. Am J Psychiatry 154: 805-811.

Broberg BV, Glenthoj BY, Dias R, Larsen DB, Olsen CK (2009). Reversal of cognitive deficits by an ampakine (CX516) and sertindole in two animal models of schizophrenia-sub-chronic and early postnatal PCP treatment in attentional set-shifting. Psychopharmacology 206: 631-640.

Broberg BV, Oranje B, Glenthoj BY, Fejgin K, Plath N, Bastlund JF (2010). Assessment of auditory sensory processing in a neurodevelopmental animal model of schizophrenia-gating of auditory-evoked potentials and prepulse inhibition. Behav Brain Res 213: 142-147.

Cardin JA, Carlen M, Meletis K, Knoblich U, Zhang F, Deisseroth K et al (2009). Driving fast-spiking cells induces gamma rhythm and controls sensory responses. Nature 459: 663-667.

Cho RY, Konecky RO, Carter CS (2006). Impairments in frontal cortical gamma synchrony and cognitive control in schizophrenia. Proc Natl Acad Sci USA 103: 19878-19883.

Clementz BA, Sponheim SR, Iacono WG, Beiser M (1994). Resting EEG in first-episode schizophrenia patients, bipolar psychosis patients, and their first-degree relatives. Psychophysiology 31: 486-494.

Costa L, Bauer L (1997). Quantitative electroencephalographic differences associated with alcohol, cocaine, heroin and dualsubstance dependence. Drug Alcohol Depend 46: 87-93.

Dissanayake DW, Zachariou M, Marsden CA, Mason R (2009). Effects of phencyclidine on auditory gating in the rat hippocampus and the medial prefrontal cortex. Brain Res 1298: 153-160.

Driesen NR, McCarthy G, Bhagwagar Z, Bloch M, Calhoun V, D'Souza DC et al (2013). Relationship of resting brain hyperconnectivity and schizophrenia-like symptoms produced by the NMDA receptor antagonist ketamine in humans. Mol Psychiatry 18: 1199-1204.

Egerton A, Reid L, McGregor S, Cochran SM, Morris BJ, Pratt JA (2008). Subchronic and chronic PCP treatment produces temporally distinct deficits in attentional set shifting and prepulse inhibition in rats. Psychopharmacology 198: 37-49.

Ehrlichman RS, Gandal MJ, Maxwell CR, Lazarewicz MT, Finkel LH, Contreras D et al (2009a). N-methyl-d-aspartic acid receptor antagonist-induced frequency oscillations in mice recreate pattern of electrophysiological deficits in schizophrenia. Neuroscience 158: 705-712.

Ehrlichman RS, Luminais SN, White SL, Rudnick ND, Ma N, Dow $\mathrm{HC}$ et al (2009b). Neuregulin 1 transgenic mice display reduced mismatch negativity, contextual fear conditioning and social interactions. Brain Res 1294: 116-127.
Featherstone RE, Liang Y, Saunders JA, Tatard-Leitman VM, Ehrlichman RS, Siegel SJ (2012). Subchronic ketamine treatment leads to permanent changes in EEG, cognition and the astrocytic glutamate transporter EAAT2 in mice. Neurobiol Dis 47: 338-346.

Freedman R, Adler LE, Waldo MC, Pachtman E, Franks RD (1983). Neurophysiological evidence for a defect in inhibitory pathways in schizophrenia: comparison of medicated and drug-free patients. Biol Psychiatry 18: 537-551.

Hakami T, Jones NC, Tolmacheva EA, Gaudias J, Chaumont J, Salzberg M et al (2009). NMDA receptor hypofunction leads to generalized and persistent aberrant gamma oscillations independent of hyperlocomotion and the state of consciousness. PloS One 4: e6755.

Hanania T, Hillman GR, Johnson KM (1999). Augmentation of locomotor activity by chronic phencyclidine is associated with an increase in striatal NMDA receptor function and an upregulation of the NR1 receptor subunit. Synapse 31: 229-239.

Hertzmann M, Reba RC, Kotlyarov EV (1990). Single photon emission computed tomography in phencyclidine and related drug abuse. Am J Psychiatry 147: 255-256.

Homayoun H, Moghaddam B (2007). NMDA receptor hypofunction produces opposite effects on prefrontal cortex interneurons and pyramidal neurons. J Neurosci 27: 11496-11500.

Hong LE, Buchanan RW, Thaker GK, Shepard PD, Summerfelt A (2008a). Beta $(\sim 16 \mathrm{~Hz})$ frequency neural oscillations mediate auditory sensory gating in humans. Psychophysiology 45: 197-204.

Hong LE, Summerfelt A, Buchanan RW, O’Donnell P, Thaker GK, Weiler MA et al (2010). Gamma and delta neural oscillations and association with clinical symptoms under subanesthetic ketamine. Neuropsychopharmacology 35: 632-640.

Hong LE, Summerfelt A, Mitchell BD, McMahon RP, Wonodi I, Buchanan RW et al (2008b). Sensory gating endophenotype based on its neural oscillatory pattern and heritability estimate. Arch Gen Psychiatry 65: 1008-1016.

Hong LE, Summerfelt A, Mitchell BD, O’Donnell P, Thaker GK (2012). A shared low-frequency oscillatory rhythm abnormality in resting and sensory gating in schizophrenia. Clin Neurophysiol 123: 285-292.

Kittelberger K, Hur EE, Sazegar S, Keshavan V, Kocsis B (2012). Comparison of the effects of acute and chronic administration of ketamine on hippocampal oscillations: relevance for the NMDA receptor hypofunction model of schizophrenia. Brain Struct Funct 217: 395-409.

Krystal JH, Karper LP, Seibyl JP, Freeman GK, Delaney R, Bremner JD et al (1994). Subanesthetic effects of the noncompetitive NMDA antagonist, ketamine, in humans. Psychotomimetic, perceptual, cognitive, and neuroendocrine responses. Arch Gen Psychiatry 51: 199-214.

Kwon JS, O'Donnell BF, Wallenstein GV, Greene RW, Hirayasu Y, Nestor PG et al (1999). Gamma frequency-range abnormalities to auditory stimulation in schizophrenia. Arch Gen Psychiatry 56: 1001-1005.

Lahti AC, Koffel B, LaPorte D, Tamminga CA (1995). Subanesthetic doses of ketamine stimulate psychosis in schizophrenia. Neuropsychopharmacology 13: 9-19.

Lazarewicz MT, Ehrlichman RS, Maxwell CR, Gandal MJ, Finkel LH, Siegel SJ (2010). Ketamine modulates theta and gamma oscillations. J Cogn Neurosci 22: 1452-1464.

Lee PR, Brady DL, Shapiro RA, Dorsa DM, Koenig JI (2005). Social interaction deficits caused by chronic phencyclidine administration are reversed by oxytocin. Neuropsychopharmacology 30: 1883-1894.

Luby ED, Cohen BD, Rosenbaum G, Gottlieb JS, Kelly R (1959). Study of a new schizophrenomimetic drug; Sernyl. AMA Arch Neurol Psychiatry 81: 363-369.

Luck SJ, Mathalon DH, O'Donnell BF, Hamalainen MS, Spencer $\mathrm{KM}$, Javitt DC et al (2011). A roadmap for the development and 
validation of event-related potential biomarkers in schizophrenia research. Biol Psychiatry 70: 28-34.

Malhotra AK, Pinals DA, Weingarten H, Sirocco K, Missar CD, Pickar D et al (1996). NMDA receptor function and human cognition: the effects of ketamine in healthy volunteers. Neuropsychopharmacology 14: 301-307.

Miyamoto S, Leipzig JN, Lieberman JA, Duncan GE (2000). Effects of ketamine, MK-801, and amphetamine on regional brain 2deoxyglucose uptake in freely moving mice. Neuropsychopharmacology 22: 400-412.

Moghaddam B, Adams B, Verma A, Daly D (1997). Activation of glutamatergic neurotransmission by ketamine: a novel step in the pathway from NMDA receptor blockade to dopaminergic and cognitive disruptions associated with the prefrontal cortex. J Neurosci 17: 2921-2927.

Monyer H, Burnashev N, Laurie DJ, Sakmann B, Seeburg PH (1994). Developmental and regional expression in the rat brain and functional properties of four NMDA receptors. Neuron 12: 529-540.

Mulert C, Kirsch V, Pascual-Marqui R, McCarley RW, Spencer KM (2011). Long-range synchrony of gamma oscillations and auditory hallucination symptoms in schizophrenia. Int J Psychophysiol 79: 55-63.

Musall S, von Pfostl V, Rauch A, Logothetis NK, Whittingstall K (2014). Effects of neural synchrony on surface EEG. Cerebral Cortex 24: 1045-1053.

O'Donnell P (2011). Adolescent onset of cortical disinhibition in schizophrenia: insights from animal models. Schizophrenia Bull 37: 484-492.

Oranje B, Gispen-de Wied CC, Verbaten MN, Kahn RS (2002). Modulating sensory gating in healthy volunteers: the effects of ketamine and haloperidol. Biol Psychiatry 52: 887-895.

Paxinos G, Watson C (1998). The rat brain in stereotaxic coordinates. Fourth edn Academic Press: San Diego.

Pinault D (2008). N-methyl d-aspartate receptor antagonists ketamine and MK-801 induce wake-related aberrant gamma oscillations in the rat neocortex. Biol Psychiatry 63: 730-735.

Rowland LM, Astur RS, Jung RE, Bustillo JR, Lauriello J, Yeo RA (2005a). Selective cognitive impairments associated with NMDA receptor blockade in humans. Neuropsychopharmacology 30: 633-639.

Rowland LM, Bustillo JR, Mullins PG, Jung RE, Lenroot R, Landgraf E et al (2005b). Effects of ketamine on anterior cingulate glutamate metabolism in healthy humans: a 4-T proton MRS study. Am J Psychiatry 162: 394-396.

Rutter L, Carver FW, Holroyd T, Nadar SR, Mitchell-Francis J, Apud J et al (2009). Magnetoencephalographic gamma power reduction in patients with schizophrenia during resting condition. Hum Brain Mapp 30: 3254-3264.
Sohal VS, Zhang F, Yizhar O, Deisseroth K (2009). Parvalbumin neurons and gamma rhythms enhance cortical circuit performance. Nature 459: 698-702.

Spencer KM, Nestor PG, Niznikiewicz MA, Salisbury DF, Shenton ME, McCarley RW (2003). Abnormal neural synchrony in schizophrenia. J Neurosci 23: 7407-7411.

Spencer KM, Niznikiewicz MA, Nestor PG, Shenton ME, McCarley RW (2009). Left auditory cortex gamma synchronization and auditory hallucination symptoms in schizophrenia. $B M C$ Neurosci 10: 85.

Stone JM, Dietrich C, Edden R, Mehta MA, De Simoni S, Reed LJ et al (2012). Ketamine effects on brain GABA and glutamate levels with $1 \mathrm{H}-\mathrm{MRS}$ : relationship to ketamine-induced psychopathology. Mol Psychiatry 17: 664-665.

Uhlhaas PJ, Linden DE, Singer W, Haenschel C, Lindner M, Maurer K et al (2006a). Dysfunctional long-range coordination of neural activity during Gestalt perception in schizophrenia. J Neurosci 26: 8168-8175.

Uhlhaas PJ, Singer W (2006b). Neural synchrony in brain disorders: relevance for cognitive dysfunctions and pathophysiology. Neuron 52: 155-168.

Uhlhaas PJ, Singer W (2010). Abnormal neural oscillations and synchrony in schizophrenia. Nat Rev Neurosci 11: 100-113.

van Berckel BN, Oranje B, van Ree JM, Verbaten MN, Kahn RS (1998). The effects of low dose ketamine on sensory gating, neuroendocrine secretion and behavior in healthy human subjects. Psychopharmacology 137: 271-281.

Vezzani A, Serafini R, Stasi MA, Caccia S, Conti I, Tridico RV et al (1989). Kinetics of MK-801 and its effect on quinolinic acidinduced seizures and neurotoxicity in rats. J Pharmacol Exp Ther 249: 278-283.

Vohs JL, Chambers RA, Krishnan GP, O’Donnell BF, Hetrick WP, Kaiser ST et al (2009). Auditory sensory gating in the neonatal ventral hippocampal lesion model of schizophrenia. Neuropsychobiology 60: 12-22.

Vollenweider FX, Leenders KL, Scharfetter C, Antonini A, Maguire P, Missimer J et al (1997). Metbolic hyperfrontality and psychopathology in the ketamine model of psychosis using emission tomography (PET) and [18F]fluorodeoxyglucose (FDG). Eur Neuropsychopharmacol 7: 9-24.

Yonezawa Y, Kuroki T, Kawahara T, Tashiro N, Uchimura H (1998). Involvement of gamma-aminobutyric acid neurotransmission in phencyclidine-induced dopamine release in the medial prefrontal cortex. Eur J Pharmacol 341: 45-56.

Zarate CA Jr, Singh JB, Carlson PJ, Brutsche NE, Ameli R, Luckenbaugh DA et al (2006). A randomized trial of an $\mathrm{N}$-methyl-D-aspartate antagonist in treatment-resistant major depression. Arc Gen Psychiatry 63: 856-864. 